\title{
Review Paper: \\ Longitudinal Kinetic and Kinematic Changes in Functional Tasks After Reconstructing Anterior Cruciate Ligament: A Systematic Review
}

\author{
Fatemeh Sharafoddin-Shirazi ${ }^{1}$ (iD), Amir Letafatkar²* (D), Zohreh Gholami ${ }^{3}$ (D)
}

1. Department of Sport Injury and Corrective Exercises, Faculty of Physical Education and Sports Sciences, Imam Reza University, Mashhad, Iran.

2. Department of Sport Injury and Corrective Exercises, Faculty of Physical Education and Sports Sciences, Kharazmi Universit, Tehran, Iran.

3. Department of Sport Injury and Corrective Exercises, Faculty of Physical Education and Sports Sciences, Kharazmi University, Karaj, Iran.

\begin{tabular}{|c|c|}
\hline $\begin{array}{l}\text { Use your device to scan } \\
\text { and read the article online }\end{array}$ & $\begin{array}{l}\text { Citation Sharafoddin-Shirazi F, Letafatkar A, Gholami Z. Longitudinal Kinetic and Kinematic Changes in Functional Tasks Af- } \\
\text { ter Reconstructing Anterior Cruciate Ligament: A Systematic Review. Journal of Exercise Science and Medicine. 2020; 12(1):1- } \\
\text { 14. http://dx.doi.org/10.32598/JESM.12.1.2 } \\
\text { doi http://dx.doi.org/10.32598/JESM.12.1.2 }\end{array}$ \\
\hline
\end{tabular}

\section{(1) (\$)}

Article info:

Received: 10 May 2019

Accepted: 17 Aug 2019

Available Online: 01 Jan 2020

Keywords:

Anterior cruciate ligament, Reconstruction, Biomechanic, Kinetic, Kinematic, Asymmetry

\begin{abstract}
Introduction: The return to sport after Anterior Cruciate Ligament Reconstruction (ACLR) is among the main issues encountered by rehabilitation medicine, injured athletes, and coaches. A main factor preventing safe return to sports is a biomechanical asymmetry between the limbs during reconstruction, which plays a significant role in the risk of re-injury. Accordingly, injury-related biomechanical changes were systematically examined in individuals with ACLR as performed functional tasks.
\end{abstract}

Materials and Methods: Articles relevant to biomechanical asymmetries between (ACLR \& uninjured) limbs in English were searched in the Google Scholar, Science Direct, PubMed MEDLINE, and Scopus databases without time limit until 2021, using the following keywords: "Anterior cruciate ligament reconstruction", "ACL reconstruction", "biomechanical", "Kinetic", "Kinematic", and "Asymmetry".

Results: In total, 122 articles were found, of which 18 met the inclusion (PRISMA) criteria. Most of the kinetic and kinematic parameters were observed in the intervals of 3, 6, 9, 12, and 18 months after ACLR between the athletes' vertical Ground Reaction Force (vGRF), peak hip abduction moment, peak knee valgus angle, peak knee flexion moment and angle, during the functional tasks; also changes were detected in the articles up to 28 months, although research in this area was limited.

Conclusion: The present systematic review suggested that biomechanical variables may vary among the limbs of patients with ACLR, between 18 and over 28 months. Accordingly, an asymmetry between the limbs increases the risk of re-injury. Therefore, a better understanding of the biomechanics of the limbs in the time intervals after ACLR can provide a safer and sooner return to sports activities.

\section{* Corresponding Author:}

Amir Letafatkar, PhD.

Address: Department of Sport Injury and Corrective Exercises, Faculty of Physical Education and Sports Sciences, Kharazmi Universit, Tehran, Iran. Tel: +98 (21) 22228001

E-mail: letafatkaramir@yahoo.com 


\section{Introduction}

he Anterior Cruciate Ligament (ACL) $\mathbf{T}$ is the most commonly injured ligament in the knee with approximately 200000 ACL ruptures per year [1-5]. Even after ACL Reconstruction (ACLR) surgery and long rehabilitation interventions, the biomechanical function of the knee joint is often not completely restored [6]. Having experienced ACL reconstruction, also, a high proportion of patients has not returned to pre-injury levels of activity and degenerative changes in the knee sooner than 10 to 20 years [7-9]. Return-to-Sports timing is a key issue, i.e., widely discussed [10]. Based on clinical reports, it is directly associated with improving the biomechanical symmetry of the limb during functional tasks at any time after ACLR $[11,12]$. Furthermore, nearly one-third of the younger cohort that resumes sports participation will sustain a second ACL injury within the first 2 years after ACLR. The incidence rate of second injuries is significantly greater in the first year, compared to the second year after ACLR. Concerning the second year, some athletes may encounter lower relative risks, such as achieving baseline joint health and function well after the current expected timeline (6-12 months) to be released in an unrestricted activity. This highlights a considerable debate in the return-to-sport decision process as to whether an athlete should wait up to 2 years to return to unrestricted sports activities after ACLR [13-15].

A series of reports indicated that the asymmetry of the limbs identified after ACLR predicts future ACL injury, especially asymmetries in sagittal plane knee moments and angles at initial contact during landing-jump tasks [16]. Additionally, side-to-side differences exist in vertical Ground-Reaction Force (vGRF) and loading rate that persisted for up to 2 years after $\operatorname{ACLR}[12,13]$. As per other studies, the difference between limbs in biomechanical variables, especially in the sagittal (knee extension angle \& moment) and frontal (knee valgus moment) planes of the knee joint during jump testing double-legged drop jump and single-legged drop jump demonstrated 9 months after ACLR [17]. In the 4-12 months after $A C L R$, the asymmetry between surgical and non-surgical limbs, reduced hip flexion and dorsiflexion angles, knee abduction moments on the side of the surgical limb was observed during drop jump landing [18]. Robert et al. outlined a symmetry increase at the sagittal plane moments at the knee and hip during a bilateral stop jump task which occurred in patients between 6 months and 1 year after ACL-R. However, the symmetry of the knee extension moment was not established until 12 months after surgery [19].

However, restoring or maintaining symmetry and performance should be considered a constant priority for both limbs, regardless of sports predictions, return to sports, and continued participation in sports [20]; this was recently associated with the risk of osteoarthritis and re-injury $[21,22]$. Due to the importance of safe return and the need to recognize the biomechanical changes of this population in the time elapsed after reconstruction during the performance of functional tasks on the second injury. No systematic review study compared kinetic and kinematic parameters examining cross-sectional and longitudinal data. Therefore, this systematic review aimed to investigate longitudinal $(3,6,9,12,18,24 \& 27$ months) kinetic and kinematic changes in functional tasks between both (the injured \& uninjured) limbs in individuals experiencing ACLR. Furthermore, we aimed to answer the following questions: How long does the biomechanical change between the limbs continue after the injury? Is the time spent on returning to pre-injury levels of activity-dependent on biomechanical changes during the reconstruction period?

\section{Materials and Methods}

\section{Criteria for selecting articles}

Having searched several databases, per Preferred Reporting Items for Systematic Reviews and Meta-Analyses (PRISMA) instructions, all the identified articles were initially added to the Endnote software, and duplicates were removed. After omitting duplicates, all titles and abstracts were reviewed to identify articles relevant to the research topic (Figure 1). The inclusion criteria of the study included research studies that have compared the kinetics and kinematics of the injured lower ACLR limb with the uninjured one as a reference as well as with healthy individuals during functional tasks in different periods. Moreover, the research population had physical activities (e.g. athletes) or any sports experience and post-reconstruction under physiotherapy supervision, including adults aged $>18$ years. The exclusion criteria consisted of failure to state the main idea, including review studies, expert opinions, studies under review, such as annual meetings, MA theses, interventions, i.e., effective on the injury, and non-biomechanical assessments that only reported performance, like differences hop distance between limbs and animal studies and functional tasks measured patients' performance. Furthermore, studies were limited to those published in English [23-28]. 


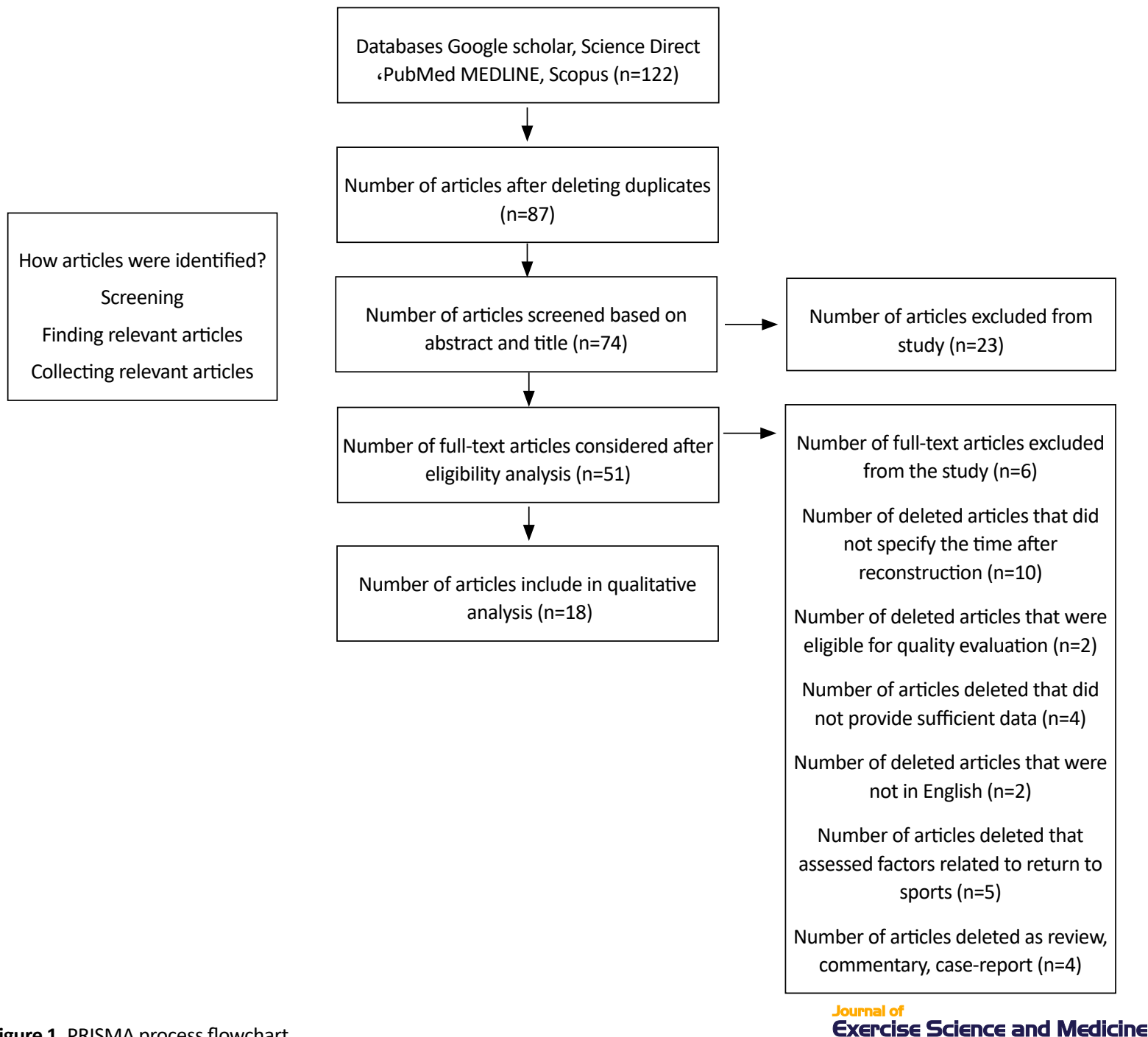

Figure 1. PRISMA process flowchart

\section{Inclusion criteria}

Studies were limited to those published in English, observational study designs (prospective cohort, casecontrol, \& cross-sectional studies) or Randomized Clinical Trials (RCTs) with a control group or comparison with the contralateral uninjured side in functional tasks, examining human subjects aged over 18 years with unilateral ACLR, without injury or deformity in the lower extremities (e.g. meniscus \& the valgus of the knee), at least 3 months after reconstruction, as well as the examination of kinetic and kinematic parameters. The studies' titles and abstracts were screened to review eligibility and reference lists of major articles searched for further relevant articles [18, 23].

\section{Data extraction}

The Physiotherapy Evidence Database (PEDro) scale was used to evaluate the quality of articles; consider- 
Table 1. Evaluating incoming articles based on PEDro scale

\begin{tabular}{|c|c|c|c|c|c|c|c|c|c|c|c|c|}
\hline Study & 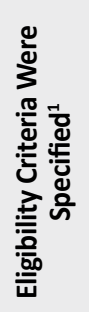 & 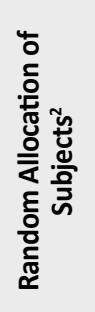 & 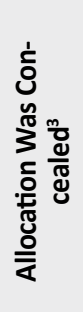 & 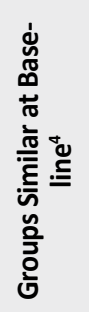 & 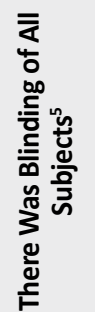 & 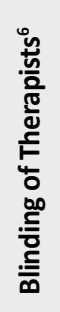 & 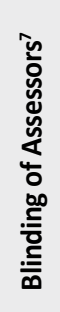 & 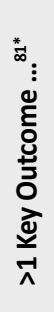 & 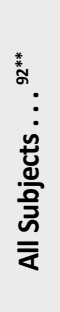 & 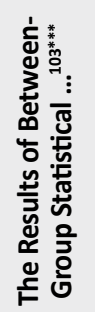 & 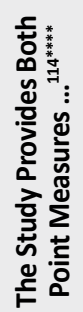 & 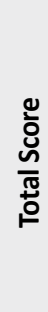 \\
\hline $\begin{array}{l}\text { Gokeler et al. } \\
\text { (2010) }\end{array}$ & 1 & - & 1 & 1 & 1 & 1 & 1 & 1 & - & 1 & 1 & 9 \\
\hline Di Stasi et al. (2013) & 1 & - & 1 & 1 & 1 & 1 & 1 & 1 & - & 1 & 1 & 8 \\
\hline Dai et al. (2012) & 1 & - & 1 & 1 & - & - & 1 & 1 & - & 1 & 1 & 7 \\
\hline $\begin{array}{c}\text { Mantashloo i et al. } \\
\text { (2019) }\end{array}$ & 1 & 1 & 1 & 1 & - & - & 1 & 1 & - & 1 & 1 & 8 \\
\hline Earl et al. (2007) & 1 & 1 & 1 & 1 & - & - & - & 1 & - & 1 & 1 & 7 \\
\hline Arhos et al. (2021) & 1 & 1 & 1 & 1 & - & - & 1 & 1 & - & 1 & 1 & 8 \\
\hline Nagelli et al. (2020) & 1 & - & 1 & 1 & - & 1 & - & 1 & - & 1 & 1 & 7 \\
\hline King et al (2019) & 1 & - & 1 & 1 & - & 1 & 1 & 1 & - & 1 & 1 & 8 \\
\hline Renner et al. (2018) & 1 & - & 1 & 1 & - & 1 & - & 1 & - & 1 & 1 & 7 \\
\hline $\begin{array}{l}\text { Mueske et al. } \\
\text { (2018) }\end{array}$ & 1 & - & 1 & 1 & - & 1 & 1 & 1 & - & 1 & 1 & 8 \\
\hline $\begin{array}{l}\text { Orishimo et al. } \\
(2010)\end{array}$ & 1 & - & 1 & 1 & - & - & 1 & 1 & - & 1 & 1 & 7 \\
\hline Butler et al. (2016) & 1 & 1 & 1 & 1 & - & 1 & 1 & 1 & - & 1 & 1 & 9 \\
\hline $\begin{array}{l}\text { Paterno et al. } \\
\quad(2010)\end{array}$ & 1 & - & 1 & 1 & - & 1 & - & 1 & - & 1 & 1 & 7 \\
\hline Curran et al. (2018) & 1 & - & 1 & 1 & 1 & - & 1 & 1 & - & 1 & 1 & 8 \\
\hline $\begin{array}{l}\text { Sharafoddin-Shirazi } \\
\text { et al. (2020) }\end{array}$ & 1 & - & 1 & 1 & 1 & 1 & 1 & 1 & 1 & 1 & 1 & 10 \\
\hline Curran et al. (2020) & 1 & 1 & 1 & 1 & - & 1 & 1 & 1 & - & 1 & 1 & 9 \\
\hline $\begin{array}{c}\text { Królikowska et al. } \\
\qquad(2018)\end{array}$ & 1 & - & 1 & 1 & - & 1 & 1 & 1 & - & 1 & 1 & 8 \\
\hline $\begin{array}{l}\text { Paterno et al. } \\
\text { (2007) }\end{array}$ & 1 & - & 1 & 1 & - & - & 1 & 1 & - & 1 & 1 & 7 \\
\hline
\end{tabular}

* $>1$ key outcome was obtained for more than $85 \%$ of subjects initially allocated to groups. ** Received the treatment or control condition as allocated or, where this was not the case, data for at least one key outcome was analysed by 'intention to treat'. *** Results of between-group statistical comparisons are reported for at least one key outcome. ${ }^{* * * *}$ The study provides both point measures and measures of variability for at least one key outcome. 
ing that the majority of articles were RCTs (Table 1). The following information was extracted from the reviewed studies: study design, sample size, study objectives, asymmetry of biomechanical variables between injured and uninjured limbs in the time elapsed after ACLR considering the type of autograft, primary outcome measures, and inclusion/exclusion criteria. The data extracted from the reviewed studies are summarized in Table 2 .

Kinetic and kinematic parameters: Knee (K), Ankle (A) hip $(H)$, Rotation (R), Peak Knee Flexion (PKF), vertical Ground Reaction Force (VGRF) and posterior Ground Reaction Force (pGRF), Peak vertical Ground Reaction Force (PvGRF), and Peak pGRF (PpGRF), Range of Motion (ROM), Peak Knee Extensor Moment (PKEM), Knee Extensor Moment (KEM), Abduction Moment (AbdM), Flexion Angle $\left(\mathrm{F}^{\circ}\right)$, Flexion Moment (FM), Peak Extension Moment (PEM), peak Power (pP), Extensor Moment (EM), Hip Internal Rotation (HIR), Knee Flexion Angle $\left(\mathrm{KF}^{\circ}\right)$, Knee Abduction Angle $\left(\mathrm{KAbd}^{\circ}\right)$, Knee Internal Rotation Angle $\left(\mathrm{KIR}^{\circ}\right)$, Hip Adduction Angle $\left(\mathrm{HAdd}^{\circ}\right)$, as well as Hip Internal Rotation Angle (HIR $)$

Functional tasks that were evaluated included the following: Stop-Jumps (SJ), Stop Jump Landing (SJL), Drop Jump Landing (DJL), Drop Vertical Jump (DVJ), Single-leg Forward Hop (SLH), Triple Hop (TH), Crossover Hop (CH), Single-leg Vertical Hop (SLVH), Double- and Single-leg Vertical Hops (D-S LVH), and Single-leg Drop (SLD)

Hamstring (HT), Bone-Patellar (PT), Quadriceps (QT), Tendon Graft (TG), and Allograft Tissue (AT)

Control group (C), Return-to-Sport (RTS)

\section{Results}

Having analyzed the relevant literature, 18 articles were ranked according to 3 overlapping groups, respectively mentioned in Table 1.

- The biomechanical evaluation of the lower limb to 6 months after ACLR (6 studies)

- The biomechanical evaluation of the lower limb to 12 months after ACLR (7 studies)

- The biomechanical evaluation of the lower limb for more than 24 months after ACLR (5 studies)

Study designs varied among these papers (retrospective, 2; case-control, 2; cross-sectional, 3; longitudinal, 2; controlled laboratory, 5; descriptive laboratory, 1; re- peated-measures, 1; prognosis, 1). In total, 252 participants were examined ( 734 ACLR \& 121 healthy individuals) to demonstrate the research purposes. Accordingly, the examined subjects reported a sports background $(n=248)[3,6,8,18,22,28,34]$. Furthermore, most articles were analyzed to comparatively evaluate the involved and non-involved limbs as well as healthy limbs; except one article which compared patients with postoperative physiotherapy supervision $<6$ months and those with postoperative physiotherapy supervision $\geq 6$ months, and control group [18]. Some articles compared the limbs in athletes who encountered a second $\mathrm{ACL}$ injury [8]. Furthermore, two articles compared biomechanics, as landing, between limbs with Hamstring Tendon (HT) autograft, Patellar Tendon (PT) autograft, Quadriceps Tendon (QT) autograft, and uncontrolled individuals following $\operatorname{ACLR}[16,21]$. Most functional task evaluations were specifically conducted as mainly focusing on landing and jumping tasks $[3,6,8,22,27,28$, 33]. Besides, some papers were explored hop tasks [3, $7,18,24,30,31,32,43]$, gait cycles [17, 34], and sidecutting tasks [9].

\section{Study characteristics}

\section{Biomechanical changes of ACLR limb up to 6 months}

By evaluating the movement patterns between the thigh, knee, and ankle when landing a single-leg hop for distance, Gokeler et al. demonstrated the maximum asymmetry between the limbs in the ROM of the knee and ankle during take-off; thus, the involved limbs, as rising, significantly reduced knee flexion and improved, accordingly. Specifically, the involved limbs significantly reduced knee flexion during the take-off and increased plantarflexion at initial contact. Furthermore, the knee extension moment was significantly lower in the involved limb. In the control group, earlier contraction onset times were significantly found for the semitendinosus, vastus lateralis, and medial gastrocnemius of the non-dominant side, compared with the dominant side. Muscle onset times were earlier and movement patterns are altered in the involved limb 6 months after ACLR [32]. There was a statistically significant difference between limbs respecting all kinetic and kinematic variables of the knee, especially knee flexion angle during initial contact and peak knee flexion in $\mathrm{ACL}$ gait patterns between involved and non-involved limbs. Besides, a clinically significant asymmetry was also identified in the hip in this group [31]. During a 35 side-cutting task, patients' surgical limb demonstrated a significant decrease in peak impact vGRF [2.55 Body Weight (BW) vs. $2.8 \mathrm{BW}$; $\mathrm{P}=0.01$ ], peak propulsion vGRF (2.15 BW vs. 2.3 


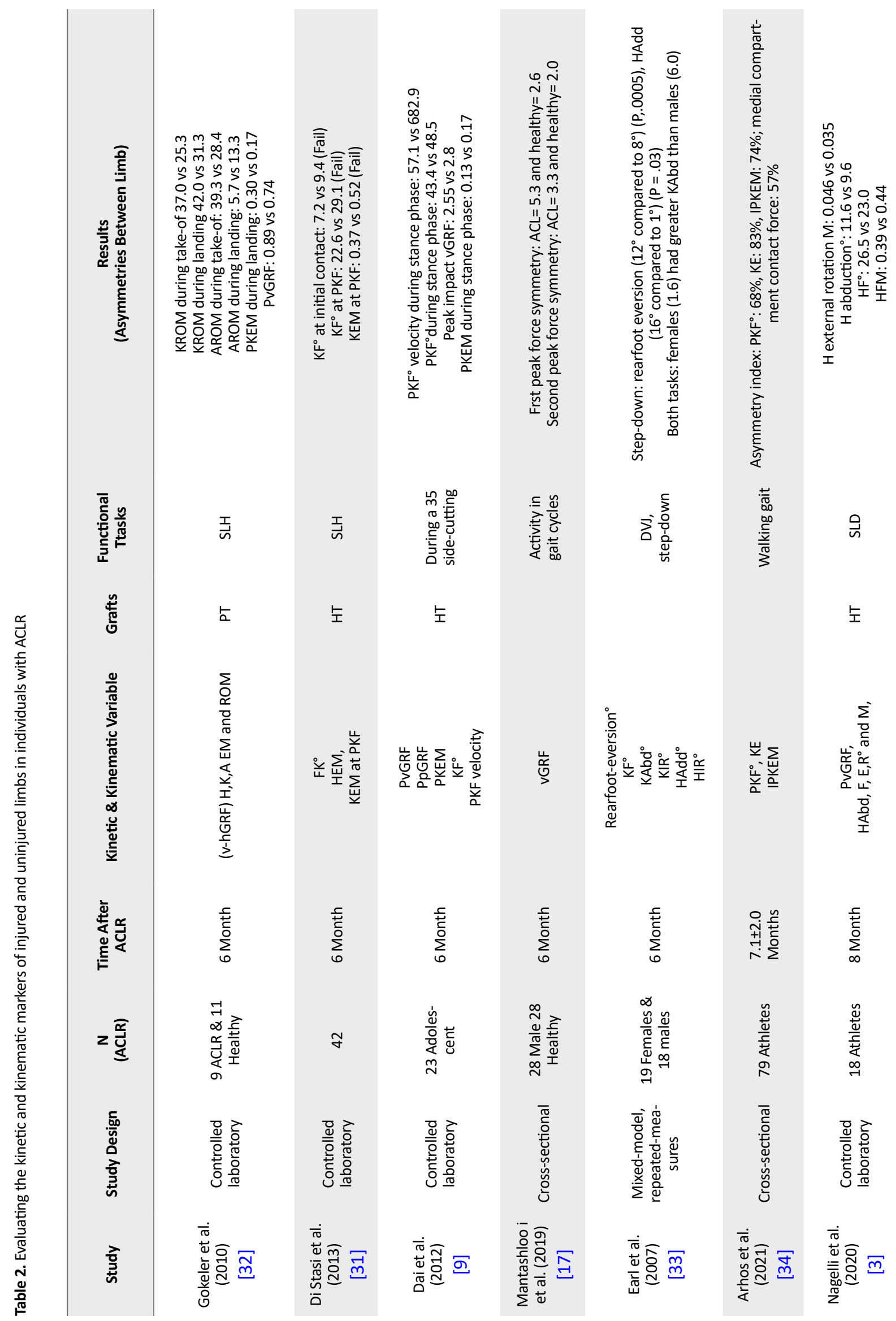




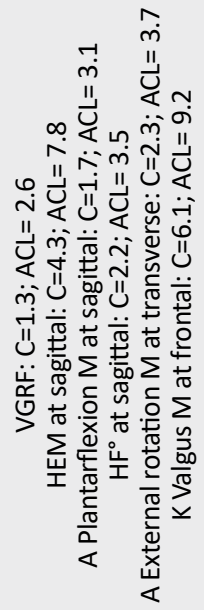

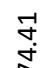

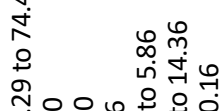

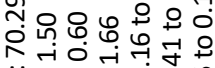

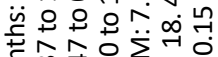

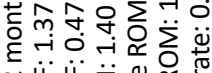

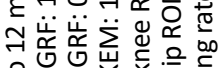

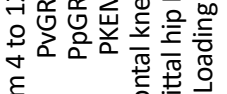

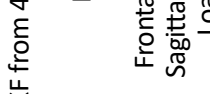

訔

$\bar{n}$

$\vec{\Delta}$

노

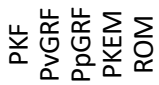

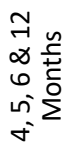

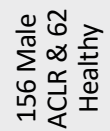

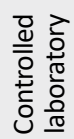

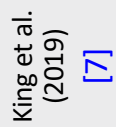

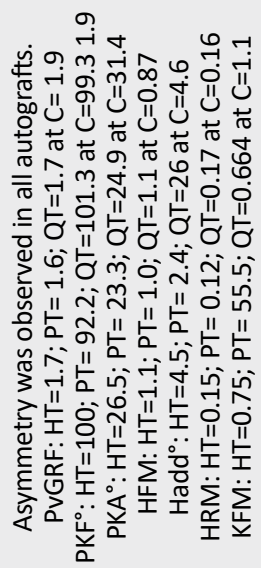

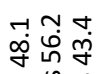

$\sum \geqslant$

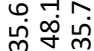

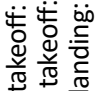

,o 00

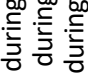

位主既

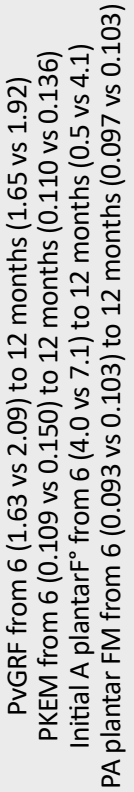

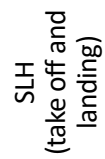

$\vec{\sim}$

占战

5

노

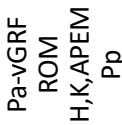

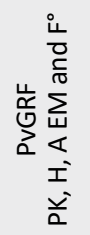

$\underset{\substack{n \\ \multirow{2}{*}{}}}{\stackrel{n}{+}}$

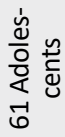

$\ddot{m}$

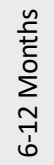

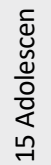

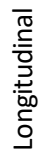

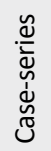

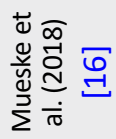

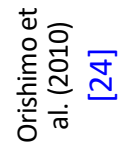




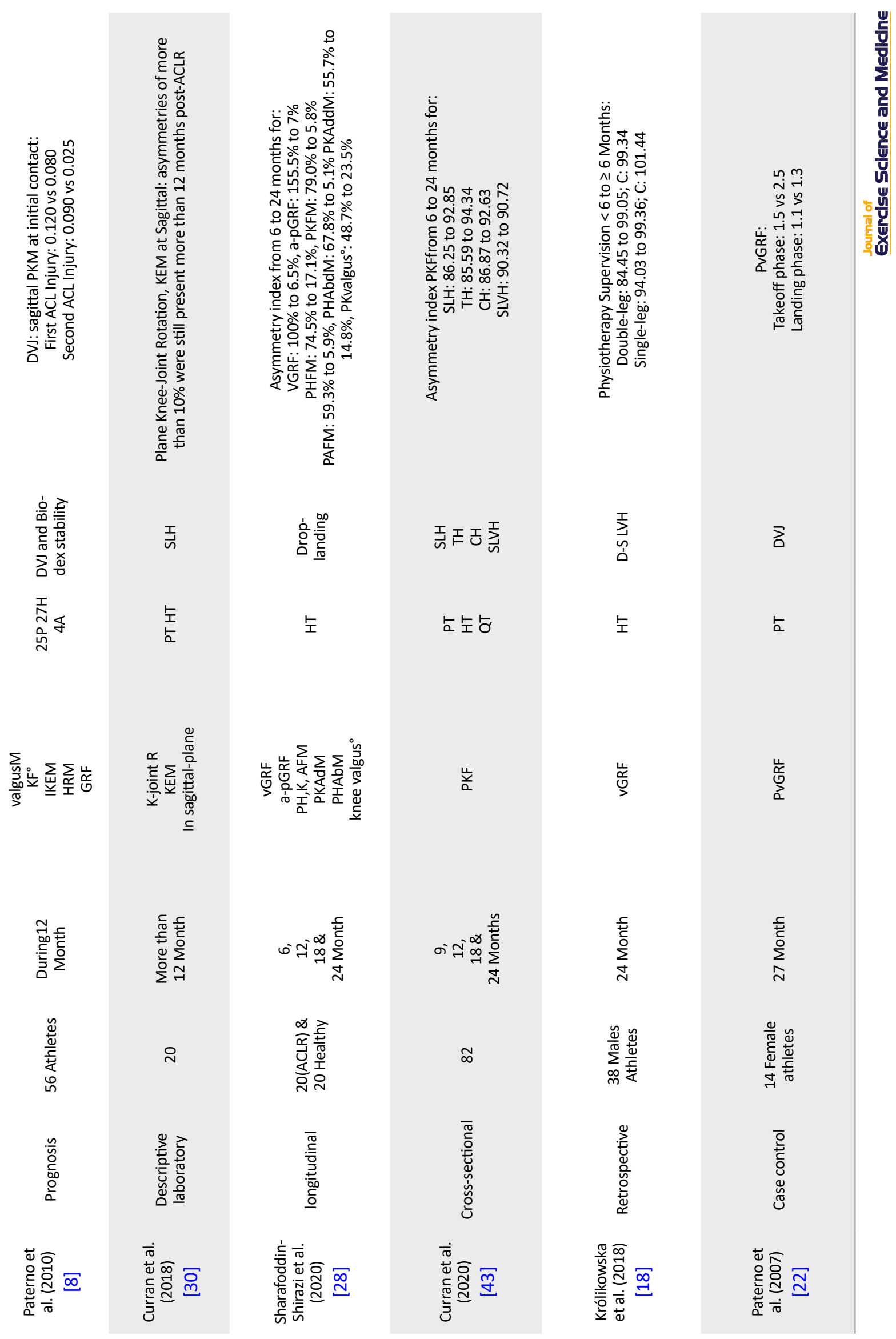


BW; $\mathrm{P}=0.01$ ), peak knee extension moment (0.13 BW 3 body height vs. $0.17 \mathrm{BW} 3 \mathrm{BH} ; \mathrm{P}=0.01$ ), and presented knee flexion angle at peak knee flexion velocity $(\mathrm{P}=0.01)$ [9]. In this regard, vGRF and muscle asymmetry were demonstrated at different stages of the gait cycle [17]. To evaluate gender-wise lower limb movement using dropvertical jump and step-down task, the step-down produced greater rear-foot eversion $\left(12^{\circ}\right.$ vs. $\left.8^{\circ}\right)(\mathrm{P}<0.0005)$ and hip adduction $\left(16^{\circ}\right.$ vs. $\left.1^{\circ}\right)(P=0.03)$, compared to the drop-vertical jump. Additionally, females performed greater hip internal rotation in the step-down than in the drop-vertical jump $\left(5^{\circ}\right.$ vs. $\left.2^{\circ}\right)(P=0.02)$. As averaged across both tasks, females had greater knee abduction, compared with males in both tasks $\left(4^{\circ}\right.$ vs. $\left.0^{\circ}\right)(P<0.0005)$ [33]. To analyze walking gait using a limb symmetry index (the value of involved limb value/uninvolved limb value $\times 100), 67 \%$ asymmetry in peak knee flexion angle and $74 \%$ internal peak knee extension moment were measured [34].

\section{Biomechanical changes of ACLR limb up to 12 months}

In a controlled laboratory study, athletes had a greater hip flexion angle (involved: 26.5 \& noninvolved: 23.0), hip external rotation moment (involved: 0.046 \& noninvolved: 0.035), hip abduction angle (involved: 11.6 \& noninvolved: 9.6), and hip flexion moment (involved: 0.39 and noninvolved: 0.44 ) in single-leg drop tasks [3]. The asymmetry indicated further biomechanical variables 9 months after ACLR in all the jump tests, compared to healthy participants. Additionally, most of the between-group differences concerned the sagittal and frontal planes, including asymmetry between the healthy and ACLR groups during double-legged drop jump, as follows: hip extension moment (healthy: 4.3 \& ACL: 7.8), ankle plantarflexion moment (healthy: 1.7 \& ACL: 3.1) hip flexion angle (healthy: 2.2 \& ACL: 3.5), ankle external rotation moment at transverse (healthy: 2.3 group \& $A C L: 3.7)$, knee valgus moment at frontal (healthy: 6.1 \& ACL: 9.2), and vGRF (healthy: 1.3 \& ACL: 2.6) [7]. As examined during a stop-jump task, the peak vGRF $(4,5, \& 6$ months $P<0.001 ; 12$ months p $1 / 40.044)$, peak knee extension moment $(5 ; 4,5, \& 6$ months $\mathrm{P}<0.001 ; 12$ months $\mathrm{p} 1 / 40.001)$ and impulse (4 \& 5 months $P<0.001 ; 6$ months $p 1 / 40.001 ; 12$ months p $1 / 40.015$ ) demonstrated a difference between the involved and uninvolved limbs sides up to 12 months after ACLR. At all the visits, the uninvolved limb impulse was higher than that of the involved limb. The loading rate ( $4 \& 5$ months $P<0.001 ; 6$ months $p$ 1/4 0.014) and peak posterior Ground Reaction Force (pGRF) ( 4 months p $1 / 40.002 ; 5$ months $p 1 / 40.022 ; 6$ months $p 1 / 40.045$ ) indicated differences up to 6 months after ACLR. Mean- while, the uninvolved limb loading rate was higher than the involved one at 4, 5, and 6 months. The involved and uninvolved limb pGRF converge at each progressive visit with a statistical difference that was present at the 4, 5, and 6-month visits; however, not manifested at the 12-month visit. Limb stiffness (4-month $p \frac{1}{4}$ 0.002, 5 months $p$ 1/4 0.047) demonstrated side-to-side differences up to 5 months after ACLR as the uninvolved limb stiffness reckoned higher than the involved limb. Accordingly, peak knee flexion was only different at the 4-month time visit, and the involved limb peak knee flexion was significantly lower than the uninvolved limb (p $1 / 40.038$ ) [6]. In the single-leg hop task, the knee moment was significantly reduced during takeoff on the involved side. Furthermore, peak moments and powers on the involved side were lower at the knee and higher at the ankle and hip, compared with the noninvolved side. However, the peak total extensor moment was not different between legs while a decrease in knee moment and increases in the ankle and hip moments were witnessed. Respecting landing, knee motion was reduced, and peak power absorbed was decreased at the knee and hip, and increased at the ankle on the involved side as compared with it on the noninvolved one [24]. Averagely, asymmetry between the limbs of fifteen adolescent patients ( 7 males $\& 8$ females, age: 15.96 1.3 years) from 6 to 12 months in stop jump task at the ankle plantarflexion angle at initial contact (involved: 4.0 \pm 13.0 ; non-involved limb: $7.1 \pm 12.2$ ) to (involved: $0.5 \pm 11.3$; non-involved limb: $4.1 \pm 13.0$ ), the peak impact VGRF (involved: $1.63 \pm 0.44$; non-involved limb: $2.09 \pm 0.57$ ) to (involved: $1.65 \pm 0.35$; non-involved limb: $1.92 \pm 0.57$ ) and the peak knee extension moment (involved: $0.109 \pm 0.030$; non-involved limb: $0.150 \pm 0.026$ ) to (involved: $0.110 \pm 0.024$; non-involved limb: $0.136 \pm 0.033)$ slightly changed; however, only the peak hip extension moment (involved: 0.170 \pm 0.052 ; noninvolved limb:0.208 \pm 0.058 ) to (involved: 0.199 \pm 0.066 ; non-involved limb: $0.196 \pm 0.069)$ had reached the symmetrical level at 12 months [27].

Of the 56 athletes who undergone ACLR in a prospective biomechanical screening, 13 suffered $A C L$ injury for the second time, and a greater asymmetry was observed in the involved limb in internal knee extension moment at initial contact as performed the drop vertical jump task of total frontal plane (valgus) movement. At initial contact in the first injury, moreover, the asymmetry between limbs in peak knee moment at sagittal was respectively 0.120 and 0.080 in the involved and the non-involved limbs, while it was respectively deemed 0.090 and 0.025 [8]. 


\section{Biomechanical changes of the ACLR limb for $>24$ months}

Compared to the healthy group, the asymmetry index from 6- to 24 months decreased in the ACLR group; specifically, peak vGRF decreased from $100 \%$ to $6.5 \%$, and anterior-pGRF reduced from $155.5 \%$ to $7 \%$. Moreover, the Al decreased for peak hip flexion, peak knee flexion, and peak ankle dorsiflexion moments were respectively recorded from $74.5 \%$ to $17.1 \%, 79.0 \%$ to $5.8 \%$, and $59.3 \%$ to $5.9 \%$. Furthermore, the Al decreased for peak hip abduction moment was from $67.8 \%$ to $5.1 \%$; it was respectively observed from $55.7 \%$ to $14.8 \%$ and $48.7 \%$ to $23.5 \%$ for peak knee adduction moment and peak knee valgus angle [28]. From 6 to 24-month asymmetry index for peak, sagittal plane knee flexion angles, triple hop, crossover hop, and single-leg vertical hop were respectively recorded from $92.85 \%$ to $86.25 \%, 94.34 \%$ to $85.59 \%, 92.63 \%$ to $86.87 \%$, and $90.72 \%$ to $90.32 \%$ during single-leg jump [43]. Besides, females who underwent ACLR demonstrated increased vGRF ( $P=0.001)$ and loading rate $(P<0.001)$ on the uninvolved limb during landing, compared with the involved limb and the control group. During takeoff, the involved limb showed significantly less ability to generate force $(P=0.03)$, compared to the uninvolved and control limbs [22].

\section{Discussion}

Reviewing selected articles relevant to injury-related biomechanical changes in ACLR individuals revealed significant kinetic and kinematic changes between the limbs of injured and healthy individuals as performing functional tasks for months following the injury. In general, the extent of biomechanical changes could be attributed to the type of activity and movement patterns before injury and rehabilitation programs in the first months after injury. Furthermore, the subset factors that will be next referred to delay the time to reach the biomechanical symmetry of the limb.

Frontal plane knee joint collapse (i.e., dynamic knee valgus) and the consequential increased internal knee adductor moments were identified as key biomechanical factors predisposing injury during landing tasks [19]. King et al. stated that athletes at risk of subsequent $\mathrm{ACL}$ injury to the uninjured reciprocal limb could be identified using biomechanical testing after ACLR [40]. A group of male athletes who returned to level 1 sports 9 months after surgery were examined. They experienced isokinetic strength testing and 3-dimensional biomechanical analysis. Regarding the Return-To-Play (RTP) process, the study participants were followed up at 2 years or second ACL injury. Results from 993 follow-up cases demonstrated that 67 of these subjects would undergo a contralateral ACL injury, and 38 of them would suffer from an ipsilateral injury. Male athletes who experienced a contralateral $A C L$ injury experienced lower quadriceps strength and biomechanical differences on the contralateral limb during double- and single-leg drop jump tests, compared with those who did not experience an injury [35]. In this regard, a research report highlighted the importance of the hip and knee joint in controlling potentially dangerous trunk and pelvic kinematics during the sidecut to prevent and rehabilitate $\mathrm{ACL}$ injuries [37].

Considering side-to-side differences in neuromuscular control of the knee during dynamic, athletic tasks were theorized to be a potential risk factor for $\mathrm{ACL}$ injury in a healthy population. These side-to-side differences in vGRF and loading rate persisted for up to 2 years after ACLR. Besides, $d$ related studies revealed that limb asymmetries identified following ACLR are predictive of future ACL injury, specifical asymmetries in sagittal plane knee moments. Injuries to the ACL often occur with the knee at low knee flexion angles. Plus, the related data suggested that the contraction of the quadriceps and hamstrings assists in providing up to $80 \%$ of the resistance to frontal plane movement at the knee $[10,26]$. Therefore, the ability of the knee to symmetrically activate the sagittal plane musculature is critical to assist in frontal plane stability during a bipedal task, when the knee is in a high-risk position of low flexion [8].

Using the Concussion Resolution Index (CRI), a controlled laboratory study measured neurocognitive performance and three-dimensional kinematic and kinetic data of the dominant limbs of 37 athletes performing an unpredictable jump-landing task. One High Performance (HP) group and one Low Performance (LP) group were neurologically screened. The LP group significantly altered neuromuscular performance during the landing phase, as a significant increase in peak vGRF, maximum peak anterior tibial shear force, knee abduction moment, and knee auction angle, as well as decreased trunk flexion angle were relatively observed. The result was reported that healthy athletes with lower neurocognitive performance develop knee kinematic and kinetic patterns which are associated with ACL injury [18, 25, 36, 38].

King et al. argued that the RTP rate was $81 \%$ in the 2-year follow-up stage after surgery [40]; of those who returned, $1.3 \%$ of those with patellar tendon grafts and $8.3 \%$ of those with hamstring grafts experienced ipsilateral rupture (hazard ratio, 0.17). In other words, the contralateral $\mathrm{ACL}$ injury rate was reckoned at $6.6 \%$. Fur- 
thermore, the findings demonstrated high overall RTP rates, lower re-injury rates with patellar tendon graft after 2-year follow-up in level 1 athletes, and no influence of time to RTP was observed on second ACL injury [40]. Grindem et al. demonstrated high overall RTP rates, lower re-injury rates with patellar tendon graft after a 2-year follow-up in level 1 athletes, and they reported no influence of time to RTP on second ACL injury [21, 41]. Johnson et al. suggested a symmetry between the lower extremities during functional tasks such as double-leg vertical hop landing in the two years after ACLR; this condition was highly correlated with the duration of postoperative physiotherapy monitoring [18]. Cronström et al. reported that as one of the 7 factors that independently increase the odds of Contra-lateral Anterior Cruciate Ligament (C-ACL) injury retaining, primary $A C L$ reconstruction was performed $\leq 3$ months following injury [38]. Additionally, delays in returning to sports for nearly 2 years significantly reduced the incidence of second ACL injuries [11].

In a 5-year follow-up, it was reported that women suffered more anterior cruciate ligament injuries than men after reconstruction and that the knee valgus angle increased concerning kinematic variables during landing jump. Moreover, the knee flexion was observed lower in the injured limb $[8,28,42]$. The incidence of injury to either knee after reconstruction was associated with younger age and higher activity levels, but returning to full activities before 6 months does not postoperatively increase the risk of subsequent injury [42].

In response to the question "can the uninvolved leg be used as a reference regardless of whether it was the dominant leg before the ACL rupture or not?" Van der Harst et al. documented no significant difference between the dominant leg and the opposite leg in healthy individuals. Besides, that the uninvolved leg of ACLR patients can be consequently used as a reference. Furthermore, they used kinetic and kinematic variables as reference values of normal differences and values between legs in healthy subjects [23].

According to the reviewed articles, biomechanical changes last between 18 and over 28 months until normal conditions can be reached in all respects. Therefore, the return-to-sport time of such individuals depends on the biomechanical changes between the limb during functional tasks after injury, and that other factors may also be effective in this delay.

\section{Conclusion}

The present systematic review findings indicated that ACLR patients display limb asymmetries in functional tasks after 18 months. It is hoped that, by identifying possible asymmetries in each month after injury, understanding the rapid and safe return to exercises and rehabilitation will be quickly reached and effectively realized.

\section{Ethical Considerations}

\section{Compliance with ethical guidelines}

Since this is a systematic review, there are no ethical principles to be observed.

\section{Funding}

This research received no specific grant from funding agencies in the public, commercial, or non-profit sectors.

\section{Authors' contributions}

All authors equally contributed to preparing this article.

\section{Conflict of interest}

The authors declared no conflicts of interest.

\section{Acknowledgments}

We would like to express our deepest appreciation for valuable assistance and contribution of all the participants.

\section{References}

[1] Pozzi F, Di Stasi S, Zeni Jr JA, Barrios JA. Single-limb drop landing biomechanics in active individuals with and without a history of anterior cruciate ligament reconstruction: A total support analysis. Clinical Biomechanics. 2017; 43:28-33. [DOI:10.1016/j.clinbiomech.2017.01.020] [PMID]

[2] Hartigan EH, Lynch AD, Logerstedt DS, Chmielewski TL, SnyderMackler L. Kinesiophobia after anterior cruciate ligament rupture and reconstruction: Noncopers versus potential copers. The Journal of Orthopaedic and Sports Physical Therapy. 2013; 43(11):821-32. [DOI:10.2519/jospt.2013.4514] [PMID] [PMCID]

[3] Nagelli C, Di Stasi S, Tatarski R, Chen A, Wordeman S, Hoffman J, et al. Neuromuscular Training improves self-reported function and single-leg landing hip biomechanics in athletes after anterior cruciate ligament reconstruction. Orthopaedic Journal of Sports Medicine. 2020; 8(10):2325967120959347. [DOI:10.1177/2325967120959347] [PMID] [PMCID] 
[4] Patterson BE, Crossley KM, Perraton LG, Kumar AS, King MG, Heerey JJ, et al. Limb symmetry index on a functional test battery improves between one and five years after anterior cruciate ligament reconstruction, primarily due to worsening contralateral limb function. Physical Therapy in Sport. 2020; 44:67-74. [DOI:10.1016/j. ptsp.2020.04.031] [PMID]

[5] Grindem H, Arundale AJ, Ardern CL. Alarming underutilisation of rehabilitation in athletes with anterior cruciate ligament reconstruction Four ways to change the game. British Journal of Sports Medicine. 2018; 52(18):1162-3. [DOI:10.1136/bjsports-2017-098746] [PMID]

[6] Renner KE, Franck CT, Miller TK, Queen RM. Limb asymmetry during recovery from anterior cruciate ligament reconstruction. Journal of Orthopaedic Research. 2018; 36(7):1887-93. [DOI:10.1002/ jor.23853] [PMID]

[7] King E, Richter C, Franklyn-Miller A, Wadey R, Moran R, Strike S. Back to normal symmetry? Biomechanical variables remain more asymmetrical than normal during jump and change-of-direction testing 9 months after anterior cruciate ligament reconstruction. The American Journal of Sports Medicine. 2019; 47(5):1175-85. [DOI:10.1177/0363546519830656] [PMID]

[8] Paterno MV, Schmitt LC, Ford Kr, Rauh MJ, Myer GD, Huang B, et al. Biomechanical measures during landing and postural stability predict second anterior cruciate ligament injury after anterior cruciate ligament reconstruction and return to sport. The American Journal of Sports Medicine. 2010; 38(10):1968-78 [DOI:10.1177/0363546510376053] [PMID] [PMCID]

[9] Dai B, Butler RJ, Garrett WE, Queen RM. Anterior cruciate ligament reconstruction in adolescent patients: Limb asymmetry and functional knee bracing. The American Journal of Sports Medicine. 2012; 40(12):2756-63. [DOI:10.1177/0363546512460837] [PMID]

[10] Pua YH, Mentiplay BF, Clark RA, Ho JY. Associations among quadriceps strength and rate of torque development 6 weeks post anterior cruciate ligament reconstruction and future hop and vertical jump performance: A prospective cohort study. Journal of Orthopaedic \& Sports Physical Therapy. 2017; 47(11):845-52. [DOI:10.2519/ jospt.2017.7133] [PMID]

[11] Nagelli CV, Hewett TE. 2017. Should return to sport be delayed until 2 years after anterior cruciate ligament reconstruction? Biological and functional considerations. Sports Medicine. 2017; 47(2):221-32. [DOI:10.1007/s40279-016-0584-z] [PMID] [PMCID]

[12] Sritharan P, Schache AG, Culvenor AG, Perraton LG, Bryant AL, Crossley KM. Between-limb differences in patellofemoral joint forces during running at 12 to 24 months after unilateral anterior cruciate ligament reconstruction. The American Journal of Sports Medicine. 2020; 48(7):1711-9. [DOI:10.1177/0363546520914628] [PMID]

[13] Wellsandt E, Gardinier ES, Manal K, Axe MJ, Buchanan TS, Snyder-Mackler L. Decreased knee joint loading associated with early knee osteoarthritis after anterior cruciate ligament injury. The American Journal of Sports Medicine. 2016; 44(1):143-51. [DOI:10.1177/0363546515608475] [PMID] [PMCID]

[14] Dingenen B, Gokeler A. Optimization of the return-to-sport paradigm after anterior cruciate ligament reconstruction: A critical step back to move forward. Sports Medicine. 2017; 47(8):1487-500. [DOI:10.1007/s40279-017-0674-6] [PMID]

[15] Patterson B, Culvenor AG, Barton CJ, Guermazi A, Stefanik J, Morris $\mathrm{HG}$, et al. Poor functional performance 1 year after ACL reconstruction increases the risk of early osteoarthritis progression. British Journal of Sports Medicine. 2020; 54(9):546-53. [DOI:10.1136/ bjsports-2019-101503] [PMID]
[16] Mueske NM, VandenBerg CD, Pace JL, Katzel MJ, Zaslow TL., Padilla RA, et al. Comparison of drop jump landing biomechanics and asymmetry among adolescents with hamstring, patellar and quadriceps tendon autografts for anterior cruciate ligament reconstruction. The Knee. 2018; 25(6):1065-73. [DOI:10.1016/j. knee.2018.09.005] [PMID]

[17] Mantashloo Z, Letafatkar A, Moradi M. Vertical ground reaction force and knee muscle activation asymmetries in patients with $\mathrm{ACL}$ reconstruction compared to healthy individuals. Knee Surgery, Sports Traumatology, Arthroscopy. 2020; 28(6):2009-14. [DOI:10.1007/s00167-019-05743-5] [PMID]

[18] Królikowska A, Czamara A, Reichert P. Between-limb symmetry during double-leg vertical hop landing in males an average of two years after ACL reconstruction is highly correlated with postoperative physiotherapy supervision duration. Applied Sciences. 2018; 8(12):2586. [DOI:10.3390/app8122586]

[19] Cesar GM, Tomasevicz CL, Burnfield JM. Frontal plane comparison between drop jump and vertical jump: Implications for the assessment of ACL risk of injury. Sports Biomechanics. 2016; 15(4):440-9. [DOI:10.1080/14763141.2016.1174286] [PMID]

[20] Chicorelli AM, Micheli LJ, Kelly M, Zurakowski D, MacDougall R. Return to sport after anterior cruciate ligament reconstruction in the skeletally immature athlete. Clinical Journal of Sport Medicine. 2016; 26(4):266-71. [DOI:10.1097/JSM.0000000000000275] [PMID]

[21] Miles JJ, King E, Falvey ÉC, Daniels KA. Patellar and hamstring autografts are associated with different jump task loading asymmetries after $\mathrm{ACL}$ reconstruction. Scandinavian Journal of Medicine \& Science in Sports. 2019; 29(8):1212-22. [DOI:10.1111/ sms.13441] [PMID]

[22] Paterno MV, Ford KR, Myer GD, Heyl R, Hewett TE. Limb asymmetries in landing and jumping 2 years following anterior cruciate ligament reconstruction. Clinical Journal of Sport Medicine. 2007; 17(4):258-62. [DOI:10.1097/JSM.0b013e31804c77ea] [PMID]

[23] van der Harst JJ, Gokeler A, Hof AL. Leg kinematics and kinetics in landing from a single-leg hop for distance. A comparison between dominant and non-dominant leg. Clinical Biomechanics. 2007; 22(6):674-80. [DOI:10.1016/j.clinbiomech.2007.02.007] [PMID]

[24] Orishimo KF, Kremenic IJ, Mullaney MJ, McHugh MP, Nicholas SJ. Adaptations in single-leg hop biomechanics following anterior cruciate ligament reconstruction. Knee Surgery, Sports Traumatology, Arthroscopy. 2010; 18(11):1587-93. [DOI:10.1007/s00167-0101185-2] [PMID]

[25] Almonroeder TG, Jayawickrema J, Richardson CT, Mercker KL. The influence of attentional focus on landing stiffness in female athletes: A cross-sectional study. International Journal of Sports Physical Therapy. 2020; 15(4):510-8. [DOI:10.26603/ijspt20200510]

[26] Wilk KE, Macrina LC, Cain EL, Dugas JR, Andrews JR. Recent advances in the rehabilitation of anterior cruciate ligament injuries. Journal of Orthopaedic \& Sports Physical Therapy. 2012; 42(3):153-71. [DOI:10.2519/jospt.2012.3741] [PMID]

[27] Butler RJ, Dai B, Huffman N, Garrett WE, Queen RM. Lower extremity movement differences persist after anterior cruciate ligament reconstruction and when returning to sports. Clinical Journal of Sport Medicine. 2016; 26(5):411-6. [DOI:10.1097/ JSM.0000000000000279] [PMID]

[28] Sharafoddin-Shirazi F, Letafatkar A, Hogg J, Saatchian V. Biomechanical asymmetries persist after $\mathrm{ACL}$ reconstruction: Results of a 2-year study. Journal of Experimental Orthopaedics. 2020; 7(1):1-10. [DOI:10.1186/s40634-020-00301-2] [PMID] [PMCID] 
[29] Nyland J, Doral MN, Caborn DNM. Anterior cruciate ligament surgery and rehabilitation: Does anybody really know what time it is? Knee Surgery, Sports Traumatology, Arthroscopy. 2020; 29(4):1015-7. [DOI:10.1007/s00167-020-06364-z] [PMID] [PMCID]

[30] Curran MT, Lepley LK, Palmieri-Smith RM. Continued improvements in quadriceps strength and biomechanical symmetry of the knee after postoperative anterior cruciate ligament reconstruction rehabilitation: Is it time to reconsider the 6-month return-toactivity criteria? Journal of Athletic Training. 2018; 53(6):535-44. [DOI:10.4085/1062-6050-478-15] [PMID] [PMCID]

[31] Di Stasi SL, Logerstedt D, Gardinier ES, Snyder-Mackler L. Gait patterns differ between ACL-reconstructed athletes who pass returnto-sport criteria and those who fail. The American Journal of Sports Medicine. 2013; 41(6):1310-8. [DOI:10.1177/0363546513482718] [PMID] [PMCID]

[32] Gokeler A, Hof AL, Arnold MP, Dijkstra PU, Postema K, Otten E. Abnormal landing strategies after $\mathrm{ACL}$ reconstruction. Scandinavian Journal of Medicine \& Science in Sports. 2010; 20(1):e12-9. [DOI:10.1111/j.1600-0838.2008.00873.x] [PMID]

[33] Earl JE, Monteiro SK, Snyder KR. Differences in lower extremity kinematics between a bilateral drop-vertical jump and a single-leg step-down. Journal of Orthopaedic \& Sports Physical Therapy. 2007; 37(5):245-52. [DOI:10.2519/jospt.2007.2202] [PMID]

[34] Arhos EK, Capin JJ, Buchanan TSSnyder-Mackler, L. Quadriceps strength symmetry does not modify gait mechanics after anterior cruciate ligament reconstruction, rehabilitation, and returnto-sport training. The American Journal of Sports Medicine. 2021; 49(2):417-25. [DOI:10.1177/0363546520980079] [PMID] [PMCID]

[35] King E, Richter C, Daniels KA, Franklyn-Miller A, Falvey E, Myer GD, et al. Can biomechanical testing after anterior cruciate ligament reconstruction identify athletes at risk for subsequent $\mathrm{ACL}$ injury to the contralateral uninjured limb? The American Journal of Sports Medicine. 2021; 49(3):609-19. [DOI:10.1177/0363546520985283] [PMID]

[36] Herman D.C, Barth JT. Drop-jump landing varies with baseline neurocognition: Implications for anterior cruciate ligament injury risk and prevention. The American Journal of Sports Medicine. 2016; 44(9):2347-53. [DOI:10.1177/0363546516657338] [PMID] [PMCID]

[37] Whyte EF, Richter C, O'Connor S, Moran KA. Investigation of the effects of high-intensity, intermittent exercise and unanticipation on trunk and lower limb biomechanics during a side-cutting maneuver using statistical parametric mapping. The Journal of Strength \& Conditioning Research. 2018; 32(6):1583-93. [DOI:10.1519/ JSC.0000000000002567] [PMID]

[38] Cronström A, Tengman E, Häger CK. Risk factors for contralateral secondary anterior cruciate ligament injury: A systematic review with meta-analysis. Sports Medicine. 2021; 51(7):1419-38. [DOI:10.1007/s40279-020-01424-3] [PMID] [PMCID]

[39] Johnson AK, Palmieri-Smith RM, Lepley LK. Contribution of neuromuscular factors to quadriceps asymmetry after anterior cruciate ligament reconstruction. Journal of Athletic Training. 2018; 53(4):347-54. [DOI:10.4085/1062-6050-463-16] [PMID] [PMCID]

[40] King E, Richter C, Jackson M, Franklyn-Miller A, Falvey E, Myer GD. et al. Factors influencing return to play and second anterior cruciate ligament injury rates in level 1 athletes after primary anterior cruciate ligament reconstruction: 2-year follow-up on 1432 reconstructions at a single center. The American Journal of Sports Medicine. 2020; 48(4):812-24. [DOI:10.1177/0363546519900170] [PMID]

[41] Grindem H, Snyder-Mackler L, Moksnes H, Engebretsen L, Risberg MA. Simple decision rules can reduce reinjury risk by $84 \%$ after
ACL reconstruction: The Delaware-Oslo $\mathrm{ACL}$ cohort study. British Journal of Sports Medicine. 2016; 50(13):804-8. [DOI:10.1136/bjsports-2016-096031] [PMID] [PMCID]

[42] Shelbourne KD, Gray T, Haro M. Incidence of subsequent injury to either knee within 5 years after anterior cruciate ligament reconstruction with patellar tendon autograft. The American Journal of Sports Medicine. 2009; 37(2):246-51. [DOI:10.1177/0363546508325665] [PMID]

[43] Curran MT, Bedi A, Kujawa M, Palmieri-Smith R. A cross-sectional examination of quadriceps strength, biomechanical function, and functional performance from 9 to 24 months after anterior cruciate ligament reconstruction. The American Journal of Sports Medicine. 2020 48(10):2438-46. [DOI:10.1177/0363546520940310] [PMID] [PMCID] 
This Page Intentionally Left Blank 